\title{
ESTUDOS VIROLÓGICOS EM PACIENTES COM ESCLEROSE LATERAL AMIOTRÓFICA
}

\author{
JOSE MAURO BRAZ DE LIMA * \\ CLACDIO DE MORAES ANDRADE ** \\ LUIZ ANTONIO ALVES DURO*** \\ MARIA LUISA LOPEZ-ALVAREZ "*n* \\ NATALIA DE MESQUITA*****
}

Nos últimos 20 anos tem-se observado crescente interesse pela relação entre virus e esclerose lateral amiotrófica (ELA). Isto decorre dos seguintes fatores: descoberta da elevada incidência entre os nativos do grupo linguistico Chamorro da ilha de Guam e na península japonesa de Kii; a transmissão do Kuru e da doença de Creutzfeldt-Jakob; descoberta de estreita relação entre vírus e algumas doenças crônicas degenerativas do sistema nervoso. Contudo, já em 1925, Neri 10 questionava uma etiologia viral.

Os mecanismos patogênicos da infecção por vírus são desde há muito conhecidos e têm por base a complexa interação vírus-hospedeiro 1,35,36,49. Oldstone \& col. ${ }^{42}$ observaram em camundongos com infecção persistente por vírus da coriomeningite linfocitária, disfunção específica no mecanismo enzimático, levando a alterações do tipo degenerativo que pode ser traduzida por uma doença de evolução crônica limitada a um determinado sistema. Poderiamos citar hipoteticamente como modelos dessa enfermidade, a doença de Parkinson (metabolismo das dopaminas), esclerose em placas (disfunção metabólica da oligodendroglia, interferindo com a formação da bainha de mielina), esclerose lateral amiotrófica (alterações degenerativas dos neurônios motores das pontas anteriores da medula espinhal e esclerose do cordão antero-lateral), e diabete (acometimento das células $B$ do pâncreas).

O conceito de vírus de ação lenta foi introduzido por Björn Sigurdsson 4i em 1954 e se aplicava a uma série de doenças crônicas degenerativas do carneiro, das quais a mais importante é o "scrapie" 2, 30. Este autor estabeleceu os seguintes critérios para definir viroses de ação lenta ou infecção por vírus lento: periodo de latência de meses ou anos; doença crônica de curso prolongado e mau prognóstico; infecção limitada a um hospedeiro e lesões anatomopatológicas restritas a um órgão ou sistema. Acrescentariamos ausência de sinais infla-

\footnotetext{
Trabalho realizado no Instituto de Neurologia Deolindo Couto (Servico do Prof. Bernardo Couto) da Universidade Federal do Rio de Janeiro (INDC/UFRJ) e nos Laboratórios de Virologia e Microscopia Eletrônica do Instituto de Microbiologia da UFRJ (Diretor: Prof. Diogo Machado); * Auxiliar de Ensino do INDC/UFRJ ; ** Prof. Adjunto do IM/UFRJ; *** Mestrando em Neurologia do INDC/UFRJ; **** Responsável pelo Laboratório de Microscopia Eletrônica do IM/UFRJ; ***** Residente do INDC/UFRJ.
} 
matórios e de resposta imunológica evidenciável. Nessas formas de infecção, nem todos os postulados de Koch são satisfeitos ${ }^{31}$.

A observação de Hardlow ${ }^{25}$ quanto à semelhança anatomopatológica entre o Scrapie e o Kuru, levou Gajdusek e col. ${ }^{10}$ a demonstrar a transmissibilidade do Kuru para chimpanzés, tornando esta a primeira doença humana provocada por um virus de ação lenta. Ulteriormente, Gajdusek e Gibbs 12 e Gibbs e Gajdusek 20,22 fizeram outra importante descoberta demonstrando a etiologia infecciosa da doença de Creutzfeldt-Jakob (transmissão para chimpanzés). Em seguida, outros estudos em doenças crônicas degenerativas do sistema nervoso foram feitos, na tentativa de descobrir uma relação com vírus de ação lenta 6, 11, 13, 14, 15, 16, 23, 27, 18.

De acordo com alguns autores $2,5,6,26,29,32,33$, podemos separar em dois grupos as doenças provocadas por virus de ação lenta: as comprovadas e as suspeitas.

Assim sendo, dados mais recentes apontan a hipótese de ser a ELA de origen viral (virus de ação lenta) como viável, apesar de diversos pontos obscuros necessitarem de melhor esclarecimento 19, 21, 24, 29, 34, 41. Não podemos esquecer a experiência pioneira de Neri 40 que, acreditando numa etiologia infecciosa, inoculou uma suspensão de medula em coelhos, sem resultados positivos, experiência esta repetida por Zil'ber ${ }^{52}$, utilizando macacos, apesar de críticas ulteriores ${ }^{7,28}$, com resultados positivos, isto é, os animais desenvolveranı ao cabo de três anos, atrofia muscular progressiva e hiperreflexia, com exame anatomopatológico similar aos pacientes.

Segundo Johnson ${ }^{34}$, a ELA poderia ser considerada como representante de infecção crônica por vírus da poliomielite, uma espécie de infecção persistente. Citamos ainda o trabalho de Lipton e Canto ${ }^{3 \pi}$ relativo a uma doença semelhante em camundongos. Froment y, Wimımer so e Ornsteen ${ }^{43}$ mostram casos de ELA relacionados com quadro pós-encefálico. Austregésilo e Couto * observaram sensivel aumento de doença de Parkinson nas décadas de 30 e 40, sugerindo uma relação viral.

Gardner \& col. 18 isolaram em camundongos, vírus tipo C. Esses animais tinham apresentado paralisia por lesão celular da ponta anterior. Esse vírus do tipo C (RNA) era do grupo Oncorna virus. Andrews e Gardner 3 observaram em camundongos selvagens com sindrome paralítica, partículas virais de virus tipo C. Este material foi transmitido por inoculação a outros animais que desenvolveram quadro similar com características de doença degenerativa. Esse virus tipo $C$ foi encontrado por Viola 47 em cércbros de pacientes de Guam. Costa \& col. 8 relataram os casos de dois irmãos, um com leucemia e o outro com amiotrofia espinhal progressiva, com indícios de infecção por vírus tipo $C$, grupo Oncorna. Esses achados não foram confirmados por Gardner e Henderson ${ }^{17}$.

Müller e Hilgenstock 39 mostraram o isolamento de um vírus do grupo arbovírus (TbE complex) a partir do liquido cefalorraqueano (LCR) de um 
paciente com 38 anos. Utilizando o mesmo material, Poussepp e Rives 45 realizaram estudo de inoculação en coelhos, sem resultados positivos. Ao examinar fragmentos musculares com microscópio eletrônico, Oshiro e col. 44 encontraran partículas do grupo picornavírus. Wolfgram ${ }^{51}$ mostrou que $50 \%$ dos soros de pacientes com ELA apresentam toxicidade para células da ponta anterior da medula (cultura de tecido em monocamadas). Recentemente tem-se pesquisado a relação dos antígenos de histocompatibilidade (HLA) com a ELA, havendo relatos de HLA-A3 e HLA-BW35 aumentadus.

\section{MATERIAL E METODOS}

Não obstante outros autores terem utilizado fragmentos de encéfalo e/ou medula para inoculação em anínais, julgamos válida a inoculação de LCR em camundongos recêm-nascidos. As tentativas de isolamento da unostra viral foram realizadas em LCR de pacientes internados no INDC/UFRJ, retirado por meio de punção lombar e acondicionado assepticamente em cubas com gelo, levadas de imediato ao IM/UFRJ, onde eram estocudas a -iouc. A inoculação foi feita em camundongros suiços brancos con 1 a 2 dias de idade, por via intracerebral, com o LCR diluido a 1/10, voiune/volume, em P.B.S. (salina fosfato tamponada), contendo albumina bovina fracão $V$ (Armour) a $0,75 \%$, antibióticos (penicilina e estreptomicina) e fungistático (fungizona). A dose foí dc 0,02 nl, usando-se seringa B.D. Champion de $1 / 4 \mathrm{ml}$ e agulha de $0,5 \times 5$.

Um grupo de animais com as mesmas condicões foi inoculado com material idéntico e sem o LCR, na mesma dose e pela mesma via, a fim de servirem de grupo controle.

Os animais inoculados com LCR, foram observados por un perífodo de 10 dias. Neste periodo, os que apresentavam alterações (paralisias) foram sucrificados, coletando-se o cérebro para passagens ulteriores. Os que não apresentaram tais alterações foran igualmente sacrificados e coletados cérebros para as passagens cegras.

Os cérebros foram estucados a $-700 \mathrm{C}$ e no mumento de uso furam diluidos a $10 \%$ (peso/volume) em PBS/albumina a $0,75 \%$, antibióticos e fungistático. En scécuida, foram triturados em Ten Broeck (triturador de vidro) evitando-se os triturados de alta rotação dado o risco de formação de aerosóis. A suspensão obtida foi centrifugada a $8000 \mathrm{x}$ g, durante 30 minutos a $40 \mathrm{C}$. O sobrenadante foil estocado a $-700 \mathrm{C}$.

Os animais controle (seis para cada grupo inuculado nas 26 passaistin:), foram observadus de rotina, sem constatação de qualquer anormalidade.

Pura melhores esclarecimentos sobre o preparo de cada sulucão vide Lima :lu.

\section{RRSULTADOS}

Foram, pois, inoculados 704 animais com material proveniente de 9 pacientes. O LCR foil o preferido devido às dificuldades de se conseguir necrópsias em nosso meio.

Consideramos como resultados positivus mudanças no comportamento motor dos animais: dificuldade em se locomoverem e se equilibrarem (paralisias) comparados com os do grupo controle. Aqueles que apresentavam resultados positivos erum sacrificados. 
Destes, retiravam-se fragmentos de cérebros que eram utilizados em parte para estudos histológicos e ultraestruturais e, em parte, para novas reinoculaçóes.

Conforme node ser observado na tabela 1, os casos de número 1, 2, 6, 7 e 9 mostraram positividade n̊ primeira passagem. A resposta năo fol quantitativamente positiva para todos, sendo expressa em números de camundongos acometidos de alteração motora logo apos o teste (inoculaçăo). Desse modo, por exemplo, no caso 1 foram inoculados 36 camundongos, tendo 23 apresentado sinais de acometimento motor $(63,8 \%)$. Na segunda e terceira passagens, apenas os casos 1 e 6 demonstraram positividade, sendo que os demais foram negativos. O caso 9, por motivos de ordem material, ficou somente com a primeira passagem (o estudo desse e outros casos está em andamento). Somente no caso 1 foi feita a quarta passagem com positividade: 10 dos 30 camundongos inoculados, apresentaram positividade $(33,3 \%)$. Năo nos parece haver dúvidas quanto à expressividade dos casos 1 e 6 . Nada observamos nos animais de controle que merecesse qualquer referência.

Foram realizados estudos pela mícroscopia ótíca e eletrônica nos tecidos nervoso e muscular dos animais com resultados positivos, os quais ainda não nos permitem conclusర̃es.

\section{COMFNTARIOS}

A inoculação de LCR de pacientes com ELA em camundongos recém-natos, com a finalidade de isolamento viral, não apresentou resultados conclusivos. Dos 9 pacientes estudados, somente os casos 1 e 6 apresentaram dados significantes, tendo sido obtido resultados objetivos até a terceira e quarta passagens (Tabela 1). Os casos 1 e 6 referent-se a pacientes jovens, de 38 e 28 anos de idade, com a forma bulbar evoluindo no caso $1 \mathrm{em}$ um ano.

Em virologia, a partir da terceira passagem, considera-se o resultado positivo como significativo. Porém, com os dados por nós obtidos, podemos apenas supor a existência de um fator de natureza desconhecida capaz de ser transmitido para animais de experimentação. Devemos lembrar que Johnson sugere que “... a não demınstração de vírus não afasta a possibilidade da etiologia viral".

A demonstração da transmissibilidade da doença de Creutzfeldt-Jakob e do Kuru sem que se encontrasse qualquer agente responsável pela transmissão dessas doenças, mostrou que a transmissibilidade tornou-se a principal evidência de doenças infecciosas deste tipo, o que torna nossos resultados significativos, apesar de não obtermos o isolamento de qualquer agente.

Apoiando-se nos critérios de Sigurdsson sobre a infecção por vírus de ação lenta, nos dados epidemiológicos de Kurland sobre os casos de Guam e Kii, na demonstração da natureza infecciosa das doenças de Creutzfeldt-Jakob e do Kuru, em estudos virológicos e imonológicos referentes ao aumento de HLA-A3, admitimos fortes evidências favoráveis à hipótese infecciosa (vírus de ação lenta) da ELA. 


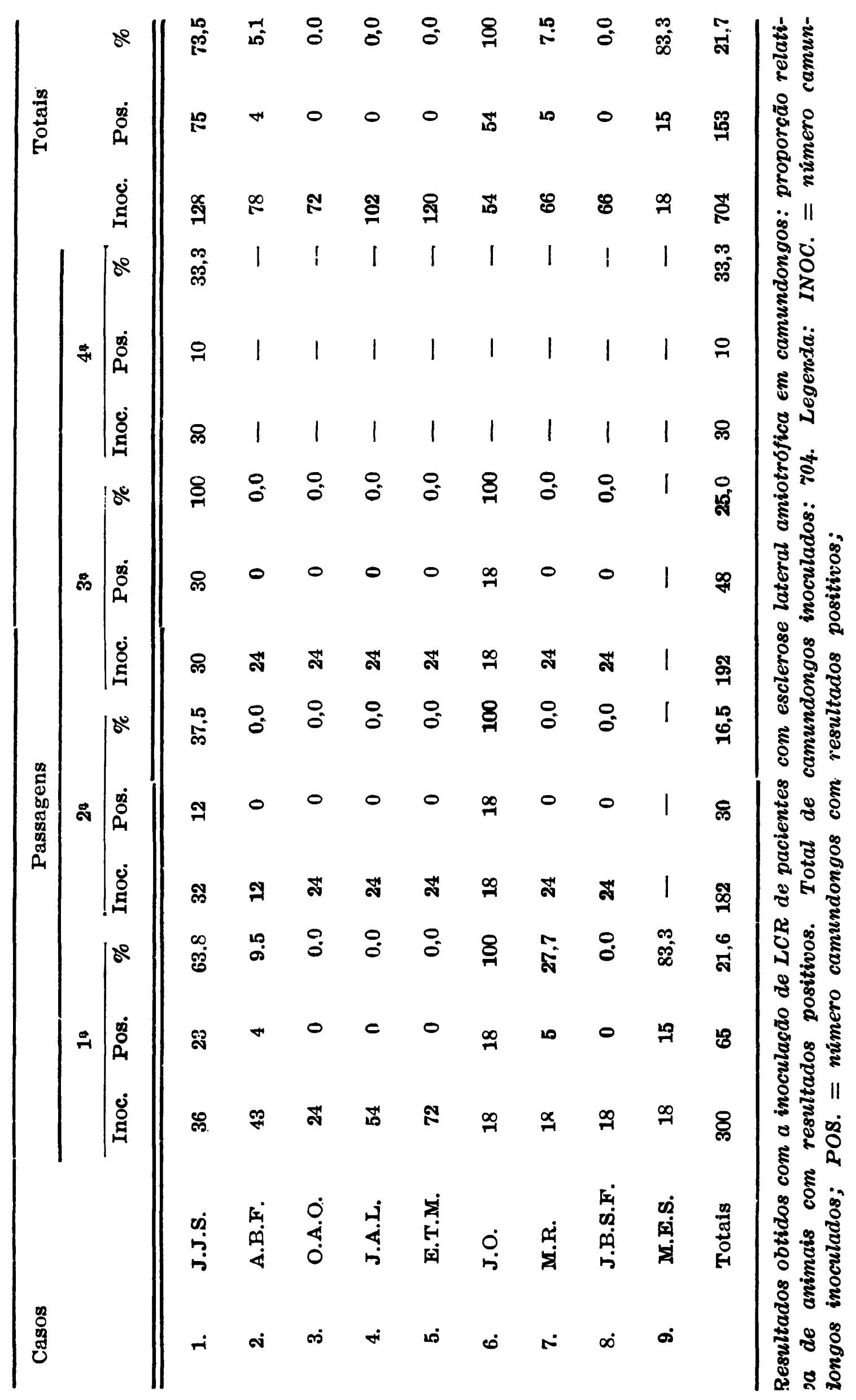




\section{RFSUMO}

São estudados os efeitos da inoculação de liquido cefalorraqueano de pacientes com ELA em camundongos recém-natos (via intracerebral). Os autores discutem os resultados encontrados, bem como a hipótese da ELA ser de natureza infecciosa (doença causada por vírus de ação lenta).

\section{STIMMARY}

Viral studies in patients with amjotrophic lateral sclerosis

The effects of intracerebral inoculation of cerebrospinal fluid in mice from 9 patients with amyotrophic lateral sclerosis are reported. There were 704 animals inoculated. The results were considered positives when the animals presented difficults in walking and equilibrating. Cases 1, 2, 6, 7 and 9 were positives in first passage. In case 1 , the positivity was reached from first to fourth passage and in case 6 , to third passage. At sight of this results, the possibility of that disease to be caused uy slow-virus is discussed.

\section{REFERPNCIAS}

1. ACTON, D. J.; KUCERA, L. S.; MIRVIK, Q. N. \& WEISSER, R. S. - Enfermidades virales de larga duraçáo. In Virologia Médica. Ed. Neuva Editorial Interamericana, México, cap. 22, 1974.

2. ADAMS, D. H. \& BELL, T. M. - Slow virc.ses. Addison-Wesley Publishing Company, Boston, 1976.

3. ANDREWS, J. M. \& GARDNER, M. B. - Murine mielopathy with motor neuron degeneration caused by an indigenous RNA tumor virus. Neurology (Minneapolis) $24: 383,1974$.

4. AUSTREghilo, A.; COUTO, D.; FILHO, A. \& COSTA. N. - Algumas consideraçỏes clínico-patológicas acerca das neuro-viroses observadas no Brasil. J. Bras. Neurol. (Rio de Janeiro) 1:363, 1949.

5. BAUER, S. - Langsame Viren und ZNS. Nervenarzt 44:393, 1973.

6. BRODANO. B. G. - I virus lenti. Giornale di Malattie Infettive e Paragsitarie $29: 711,1977$.

7. BRODY, J. A.; HADLOW, W. J.; HOTCHIN, J.; JOHNSON, R. T.; KOPROWSKY, II. \& KURLAND, R. T. - Soviet search for viruses that cause chronic neurologic discases in the U.R.S.S. Science 147:1114, 1965.

8. COSTA, J. C. ; RAsson, A. S.; TRALKE, T. S.; ENGEL, W. K.; CANELLON, G. P. \& BRATENAHE, C. G. - Leukemia and lower-motor-neuron disease. The Lancet II $(872): 107,1974$.

9. FROMENT, M. J. - Sclérose latérale amyotrophique et encephalite épidémique. Rev. Neurol. (Paris) I:842, 1925.

10. GAJDUSEK, D. C.; GIBBS, C. J. Jr. \& ALPERS, M. - Experimental transmission of a Kuru-like syndrome to chimpangles. Nature 209:794, 1966. 
11. GAJDUSEK, D. C. - Slow-virus infections of the nervous system. New England J. Med. 16:392, 1967.

12. GAJDUSEK, D. C. \& GIBBS, C. J. Jr. - Transmission of two subacute encephalopathies of man (Ki:ru and Creutzfeldt-Jakob disease) to new world monkeys. Nature 230:588, 1971.

13. GAJDUSEK, D. C. - Slow infections spongiform virus encephalopathies. J. Clin. Pathol. 25 (Suppl.): 78, 1972.

14. GAJDUSEK, D. C. - Kuru in the New Guinea Highlands. In J. D. Spillane, ed. Tropical Neurology. Oxford University Press, London, pp. 376-383, 1973

15. GAJDUSEK, D. C. - New aspects of spongiform subacute viral encephalopathies. Abstracts of the IV Congresso Pan-Americano de Neurologia, México, pp. 12-17, 1975.

16. GAJDUSEK, D. C. \& GIBBS, C. J. Jr. - Kuru, Creutzfeldt-Jakob diseases and transmissible presenile dementias. In V. Ter. Meulen \& M. Katz, eds. - Slow-virus Infections of the Central Nervous System. Springer Verlag, Berlin, pp. 15-49, 1977.

17. GARDNER, M. B. \& Henderson, B. E. - Lower motor neurone disease in mice and amyotrophic lateral sclerosis in man. The Lancet 2 (II): 952, 1974.

18. GARDNER, M. B.; RASHEED, S.; KLEMENT, J.; ROUGEY, R. W.; BROWN, C. J.; DWORSKY, R. \& HENDERSON, B. E. - Lower motor neuron disease in wild mice calised by indigenous type $\mathrm{C}$ virus and search for a similar etiology in human amyotrophic lateral sclerosis. In J. M. Andrews, R. T. Johnson \& M. A. Brazier. eds. - Amyotrophic Lateral Sclerosis Recent Research Trends. Academic Press, New York, pp. 217-234, 1976.

19. GIBBS, C. J. Jr \& GAJDUSEK, D. C. - Kuru: a prototype subacute infectious disease of the nerrous system as a model for the study of amyotrophic lateral sclerosis. In F. H. Norris \& L. T. Kurland, eds. - Motor Neuron Disease. Grune and Stratton Inc., New York, pp. 269-279. 1 669.

20. GIBBS, C. J. Jr. \& GAJDUSEK, D. C. - Infection as the etiology of spongiform encephialo,jathy (Creutzfeldt-Jakob iseasa). Science 165 (3897): 1023, 1969.

21. GIBBS, C. J. Jr. \& GAJDUSEK, D. C. - Amyotrophic lateral sclerosis, Parkingon's disease and th amyotrophic lateral sclerosis, Parkinsonism dementia complex on Guam: a review and summary of attempts to demonstrate infection as the etiology. J. Clin. Pathol. 25 (Suppl.): 132, 1972.

22. GIBBS, C. J. Jr. \& GAJDUSEK, D. C. - Isolation and characterization of the subacute spongiform virus encephalopathies of man. J. Clin. Pathol. 25 (Suppl.): 84, 19 ;2.

23. GIBBS, C. J. Jr. \& GAJDUSEK, D. C. - Biology of Kuru and Creuztfeldat-Jakob disease. In W. Zeman \& F. H. Lennette, eds. - Slow-virus disease. The Williams and Wilkins Company, Baltimore, 1974.

24. HANISCH, R.; DWORSKI, R. L. \& HENDERSON, B. E. - A search for clues to the cause of amyotrophic lateral sclerosis. Arch. Neurol. (Chicago) 33:456, 1976.

25. HARDLOW, W. J. - Scrapie and Kuru. The Lancet 2 (7097): 289, 1959.

26. HIRANO, A.; KURLAND, L. T.; KROOTHY, R. S. \& LESSEL, S. - Parkinsonism dementia complex an endemic disease on the islands of Guam. Brain 84:642, 1961. 
27. HORTA BARBOSA, L.; FUCILLO, D. A. \& SEVER, J. L. - Subacute sclerosing panensephalites: isolation of measles virus from a brain biopsy. Nature 221:974, 1969.

28. JOHNSON, R. T. - Virological studies and summary of soviet experiments on the transmission of amyotrophic lateral sclerosis to monkeys. In F. H. Norrris \& $L$. T. Kurland, eds. - Motor Neuron Disease. Grune and Stratton Inc., New York, pp. 280-285, 1969.

29. JOHNSON, R. T. \& HERNDON, R. M. - Virologic studies of multiple sclerosis and others chronic and relapsing neurological disease. Progr. Med. Virol. 18:214, 1974.

30. JOHNSON, R. T. - Slow infections: virus host relationship. In W. Zeman \& E. LENNETTE, eds. - Slow virus disease. The Williams and Wilkins Co. Baltimore, pp. 1-9, 1974.

31. JOHNSON, R. T. \& GIBBS, C. J. Jr. - Koch's postulate and slow infections of the nervous system. Arch. Neurol. (Chicago) 30:36, 1974.

32. JOHNSON, R. T. - Slow-virus infections and chronic neurological diseases. In $P$. Seeman \& G. M. Brow, eds. - Frontiers in Neurology and Neuro-science Research. University of Toronto, pp. 89-96, 1974.

33. JOHNSON, R. T. - Slow-virus diseases of the central nervous system: transmissibility vs communicability. Clinical Neurosurgery 24:590-597, 1977.

34. JOHNSON, R. T. - Virological studies of amyotrophic lateral sclerosis: an over view. In J. M. Andrews; R. T. Johnson \& M. A. Brazier, eds. - Amyotrophic Lateral Sclerosis Recent Research Trends. Academic Press, New York, pp. 173-180, 1976.

35. JOHNSON, R. T. \& GRIFFIN, D. E. - Pathogenesis of virus infections. In P. J. Vinken \& G. W. Bruyn, eds. - Handbook of Clinical Neurology: North Holland Publishing Co., London, cap. 2, 1978.

36. LIMA, J. M. B. - Contribuição para o estudo da esclerose lateral amiotrófica: aspectos clínicos, epidemiológicos e virológicos. Tese INDC/UFRJ, Río de Janeiro, 1979.

37. LIPTON, H. L. \& COUTO, M. C. B. - Theiler's virus induced central nervous system disease in mice. In J. M. Andrews; R. T. Johnson \& M. A. Brasier, eds. Amyotrophic Lateral Sclerosis: Recent Research Trends. Academic Press, New York, pp. 263-277, 1976.

38. MANZ, H. J. - Pathology and pathogenesis of viral infections of central nervous system. Human Pathology 8:3, 1977.

39. MULLER, W. K. \& HILGENSTOCK, F. - An uncommon case of amyotrophic lateral sclerosis with isolation of a virus from CSF. J. Neurol. 211:11, 1975.

40. NERI, V. - Rapport clinique sur la sclérose latérale amyotrophique. Rev. Neurol. (Paris) I: 759, 1925.

41. NORRIS, F. H. Jr. - Current status of the search for virus in amyotrophic lateral sclerosis. Abstracts of the IV Panamerican Congress of Neurology, México D. F., 1975.

42. OLDSTONE, M. B. A.; PERRIN, L. H. \& WELSH, R. M. - Potential pathogenic mechanism of injury in amyotrophic lateral sclerosis. In J. M. Andrews; R. T. Johnson \& M. A. Brazier, eds. - Amyotrophic Lateral Sclerosis: Recent Research Trends. Academic Press, New York, pp. 251-262, 1976. 
43. ORNSTEIN, A. M. - The syndrome of amyotrophic lateral sclerosis in epidemic encephalitis. J. Nervo: s and Mental Diseases 72:369, 1930.

44. OSHIRO, L. S.; CREMER, N. E.; NORRIS, F. H. \& LENNETTE, E. H. - Virus like particle in muscle from a patient with amyotrophic lateral sclerosis. Neurology (Minneapolis) 26: 67, 1976.

45. POUSSEP ET RIVES, S. - Contribuition à la pathologie et à la pathogenie de la sciérose latérale amyotrophique. Rev. Neurol. (Paris) 1:834, 1925.

46. SIGURDSSON, B. - RIDA: a chronic encephalitis of sheep: with general remarks on infections which develop slowly and some of their special characteristics. British Veterinary. (London) 110:341, 1954.

47. VIOLA, M. Y. - RNA tumor viruses as causative agents of chronic neurological disease. In J. M. Andrews, R. T. Johnson \& M. A. Brazier, eds. - Amyotrophic Lateral Sclerosis: Recent Research Tren;s. Academic Press, New York, pp. 235-249, 1976.

48. WALKER, D. L.; PADGENTT, B. L.; ZU RHEIN, Z. M.; ALBERT, A. E. \& MARSH, R. F. - Current study of an opportinistic papova virus. In W. Zeman \& E. Lennette, eds. - Slow Virus Disease. The Williams and Wilkins Co., Baltimore, 1974.

49. WEINER, L. P. \& Johnson, R. T. - Virus host clues interactions in slow virus diseases of the nervous system. In G. Poste \& G. L. Nicholson, eds. - Virus Infections and Cell S.rface. North Holland Company, Amsterdam, pp. 185-212, 1977.

50. WIMMER, M. - Amyotrophies de type sclérose latérale amyotrophique dans l'encephalite epíémique chronique. Rev. Neurol. (Paris) 1:841, 1925.

51. WOLGRAM, F. - Blind studies on the effect of amyotrophic lateral sclerosis sera on motor neurone in vitro. In J. M. Andrews; R. T. Johnson \& M. A. Brazier, eds. - Amyctrophic Lateral Sclerosis: Recent Research Trends. Academic Press, New York, pp. 145-149, 1976.

62. ZIL'BER, L. A.; BAGDAKOVA, Z. L.; GARDAS JAN, A. N.; KUNAVALOV, N. V.; BUNINA, T. L. \& BARABADZE, E. M. - Study of the etiology of amyotrophic lateral sclerosis. Bulletin of World Health Organization 29:449, 1963.

Instituto de Neurologia Deolindo Couto - Av. Venceslau Bras, 95, Botafogo 22890 Rio de Janetro, RJ - Brasil.

Instituto de Microbiologia da UFRJ - Departamento de Virologia - Centro de Ciencias da saude - Cidade Universitdria - Iha do Frundao - Rio de Jameiro, $R J$ - Brasil. 